\title{
Flexible Nasopharyngolaryngoscopy for the Assessment of Upper Airway Disorders
}

\author{
Sangita Regmi Chalise ${ }^{1}$, Subash Khadkal \\ ${ }^{1}$ Department of ENT, KIST medical college teaching hospital, Lalitpur, Nepal
}

\section{ABSTRACT}

Introduction: Upper airway problems are frequently encountered in ENT practice. It is difficult to diagnose upper airway pathology by conventional methods. So use of fibreoptic flexible nasopharyngoscopy (NPL) is very helpful in both diagnosis and treatment of upper airway disorders. The aim of this study is to observe the usefulness of flexible NPL in patients with upper airway problems as an outpatient procedure.

Materials and Methods: A cross sectional descriptive study was conducted in the department of ENT at KIST medical college teaching hospital during the period of 2 years. A total of 138 patients who had persistent upper airway symptoms and underwent NPL were included in the study. Detail history, clinical examination and required investigations were done. Data were recorded and analysed.

Results: Total 138 patients suffering from upper airway disorders underwent NPL. Among them $65(47.1 \%)$ were males and 73(52.9\%) were females. Age range was from 16 to 82 years. Most common problem observed was laryngopharyngeal reflux disease accounting for 41 percent of cases followed by vocal cord nodule and polyp.

Conclusions: Flexible fiberoptic nasopharyngolaryngoscopy (NPL) is safe and noninvasive outpatient department procedure for the assessment of upper airway disorders.

Keywords: Airyway; Fibreoptic; Flexible; Laryngopharyngeal; Nasopharyngolaryngoscope Reflux; Vocal cord
Copyright: This is an open-access article distributed under the terms of the Creative Commons Attribution 4.0 International License, which permits unrestricted use, distribution, and reproduction in any medium, provided the original author and source are credited.

\section{Correspondence:}

Dr. Sangita Regmi Chalise, MBBS, MS

Associate Professor, Department of ENT

KIST medical college teaching hospital, Lalitpur,

Nepal

ORCID ID: 0000-0001-9033-6592

E-mail: sangitaregmi@gmail.com

Submitted: $14^{\text {th }}$ September 2018

Accepted: $15^{\text {th }}$ October 2018

Published: $1^{\text {st }}$ December 2018

Conflict of Interest: None Sources of Support: None

Citation: Regmi SC, Khadka S. Flexible nasopharyngolaryngoscopy for the assessment of upper airway disorders. Nep Med J 2018;1:86-8. DOI 10.3126/nmj.v\%vi\%i.21590

\section{INTRODUCTION}

Visualization of upper airway has been area of continuous research and has been changing dynamically. Anterior rhinoscopy, posterior rhinoscopy and indirect laryngoscopy were only available tools inthe past. A flexible fibreoptic nasopharyngolaryngoscope (NPL), as an office procedure, was first introduced in $1975 .{ }^{1}$ Using the NPL, the hidden areas are easily accessible to the clinician. Since then it is being used both for diagnostic and therapeutic purposes. ${ }^{2}$ Videoendoscopy provides information about structural abnormalities, gross function and airway disorders. It is being used for treatment plan, documentation, education of patient and even monitoring the outcome of therapy. Both rigid and flexible videoendoscopies are available to access the airway. Advantage of flexible endoscope is dynamic evaluation of natural function like swallowing, speech and singing. It helps to even assess the velopharyngeal insufficiency and is an intimate part of assessment of obstructive sleep disorders. ${ }^{3}$ Thus NPL has become state of the art in the visualization of nose, nasopharynx and larynx. ${ }^{1}$ 
Table 1: Age distribution of the study population

\begin{tabular}{ccc}
\hline Age group(years) & Frequency(n) & Percentage (\%) \\
\hline $16-25$ & 20 & 14 \\
$26-35$ & 35 & 25 \\
$36-45$ & 32 & 23 \\
$46-55$ & 19 & 14 \\
$56-65$ & 11 & 8 \\
$66-75$ & 13 & 9 \\
$76-82$ & 8 & 6 \\
Total & $\mathbf{1 3 8}$ & $\mathbf{1 0 0 . 0 0}$
\end{tabular}

Table2: Flexible fibreoptic nasopharyngolaryngoscopic findings

\begin{tabular}{ccc}
\hline NPL Findings & Frequency (n) & Percentage (\%) \\
\hline Epistaxis & 7 & 5 \\
\hline Nasal polyps & 5 & 3.6 \\
\hline $\begin{array}{c}\text { Nasopharyngeal } \\
\text { carcinoma }\end{array}$ & 2 & 1.4 \\
\hline Foreign body & 2 & 1.4 \\
\hline Acute laryngitis & 3 & 2.1 \\
\hline LPRD & 53 & 38.4 \\
\hline Vocal Cord nodule & 19 & 13.7 \\
\hline Vocal Cord polyp & 12 & 8.6 \\
\hline Vocal cord palsy & 3 & 2.1 \\
\hline Rinke's edema & 8 & 5.7 \\
\hline Functional aphonia & 7 & 5 \\
\hline Laryngeal cancer & 7 & 5 \\
\hline Globus pharyngeus & 4 & 2.8 \\
\hline Tubercular laryngitis & 2 & 1.4 \\
\hline Normal & 4 & 2.8 \\
\hline
\end{tabular}

\section{MATERIALS AND METHODS}

A cross sectional descriptive study was conducted in the department of ENT at KIST medical college teaching hospital during the period of 2 years from January 2016 to December 2017. Permission was obtained from the ethical committee. A total of 138 patients who had persistent upper airway symptoms and underwent NPL were included in the study. The patient of age less than 15 years and who refused to participate in the study were excluded. Detail history, clinical examination and required investigations were done. Pentax PSV-4000®, a flexible fibreoptic nasopharyngolaryngoscope along with camera, light source and colour video monitor was used. The procedure was done in sitting position with head slightly extended. Both nasal cavities and throat were sprayed with $15 \%$ lignocaine spray 10 minutes before the procedure. The lubricated scope was passed intranasally and airway tract was serially observed upto larynx and hypopharynx for any pathologies. The data was entered into pre formed pro forma, complied, and analysis was done using SPSS 21.

\section{RESULTS}

Total 138 patients suffering from upper airway disorders were included in this study. Among them 65(47.1\%) were males and $73(52.9 \%)$ were females. Age range was from 16 to 82 years (Table 1). Among the cases most common problem observed was laryngopharyngeal reflux disease accounting for 41 percent of cases. The second most common problem was vocal cord nodule and polyp. Nasopharyngolaryngoscopy was normal in 4 patients. All other pathologies and its frequency were compiled in table 2. Minor complications like discomfort, pain and minor nasal bleeding was seen in 3 patients. However major complications that require any intervention were not seen in this study.

\section{DISCUSSION}

Upper airway disorders are commonly encountered in ENT practice. These patients are mainly treated with antihistamines and antibiotics without proper evaluation of the upper airway. Although many patients are examined with indirect laryngoscopy, this is not always conclusive and visualization is poor ${ }^{4} \mathrm{NPL}$ is the procedure by which upper airway can be examined appropriately with adequate illumination and visualization. ${ }^{5}$

The age group ranged from 16 to 82 years, maximum numbers of patients were in the age group of 26-35 years. In our study upper airway problems were more seen in females (52.9\%) than in males $(47.1 \%)$. Similar findings were seen in study done by Ahmad Nasratet al. ${ }^{6}$ In contrary, the problems were found to be more common in male $(52.2 \%)$ in a study done by Muhammad Shafi et al. ${ }^{7}$

The most common findings in this study were LPRD which was $38.4 \%$. Similar findings was observed in a study done by Wilkins et $\mathrm{al}^{8}(42.5 \%)$, but the incidence of the pathology was low in the article published by Ahmad Nasrat et $\mathrm{al}^{6}(11.4 \%)$. GERD have upper airway symptoms without heartburn in 20-60 $\%$ of patients. The most common presentation is globus but the manifestation can be vague and vary from patient to patient. So it can be misleading in clinical workup at times. ${ }^{9}$ The second most common finding was vocal cord nodule which account for 13.8 percent. Similar findings were reported by Azhar Hameed et al. ${ }^{10}$ $(12 \%)$ where such nodule was commonly seen in professionals like singers, teachers, lawyers and public speaker. The incidence of laryngeal tuberculosis was $1.4 \%$ in our series. Similar incidence was reported by Azhar Hameed et al. ${ }^{11}$ which was about $2.8 \%$. But the incidence was high $(10 \%)$ in the series reported by Farooq Ahmad. ${ }^{12}$

NPL findings were normal in $5.52 \%$ of our patients. Similarly Azhar Hameed et al. ${ }^{10}$ observed normal NPL findings in $5 \%$ of their patients. Major complications that require any intervention were not seen in our study. However minor complaints like post procedure discomfort, pain and nasal bleeding was seen in $4.14 \%$ of patients. In a study done by Wilkins et $\mathrm{al}^{8}$ minor complications like pain and mild epistaxis was reported in 1.1 percent.

\section{CONCLUSIONS}

Flexible fiberopticnasopharyngolaryngoscopy (NPL) is safe and non invasive outpatient department procedure for the assessment of upper airway disorders without serious complications. 


\section{REFERENCES}

1. Michael J. Schumacher.Fibreoptic nasopharyngolaryngoscopy: A procedure for allergists? J. Allergy Clin.Immunol 1988;5:960-2.

2. Mahbub S, Azaal- Amin, Biswas SS, Jamal MS. A study on diagnostic importance of fiber optic laryngoscopy (FOL) in patients with upper airway disorders. Journal of Bangladesh College of Physicians and Surgeons 2014;32:200-5. Crossref

3. Samlan R A, Kunduk M. Cummings Otolaryngology HEAD AND NECK SURGERY: (6th ed), Elsevier. Philadelphia: 2015. 839pp

4. Wrigley SR, Black AE, Sidhu VS. A fibreoptic laryngoscope for paediatric anaesthesia. A study to evaluate the use of the $2.2 \mathrm{~mm}$ Olympus (LF-P) intubating fibrescope. Anaesthesia1995;50:709-12. Crossref

5. Alalami AA, Ayoub CM, Baraka AS. Laryngospasm: review of different prevention and treatment modalities. PaediatrAnaesth 2008;18:281-8. Crossref

6. Ahmad Nasrat Al-juboori. The role of flexible nasolaryngoscopy in the management of persistent throat symptoms, Br J Sci 2012;6:22-7.
7. Shafi M, Shaikh AA, Ahmed J. Flexible fiberoptic nasopharyngo- laryngoscopy: Indications and Outcome. Journal of Surgery Pakistan (International) 2015;20:56-9.

8. Wilkins T, Gillies RA, Getz A, Zimmerman D, Kang L. Nasolaryngoscopy in a family medicine clinic: indications, findings, and economics. J Am Board Fam Med 2010;23(5):591-7

9. Ahuja V, Yencha MW, Lassen LF. Head and neck manifestations of gastroesophageal reflux disease. Am Fam Physician 1999;60:873-80. Crossref

10. Hameed A, Mushwani M, Sheikh S I, et al. Surgical Audit of Laryngeal Disorders Examined Through Flexible FibreopticNasopharyngocope / Laryngoscope. PJMHS 2013;7:456-59.

11. Hameed A, Aziz B, Mushwani M, et al.Clinico-etiolological Study of Hoarseness in 100 Patients. J F J M C 2013;7:8-11.

12. Farooq Ahmad Mian. Hoarseness of voice. Professional Med J 2006;13:504- 7 . 